\title{
Retraction Note: Gene expression analysis in response to osmotic stimuli in the intervertebral disc with DNA microarray
}

Wenzhi Zhang, Xu Li', Xifu Shang, Qichun Zhao, Yefeng Hu, Xiang Xu, Rui He, Liqun Duan and Feng Zhang

\section{Retraction}

The Publisher and Editor regretfully retract this article [1] because the peer-review process was inappropriately influenced and compromised. As a result, the scientific integrity of the article cannot be guaranteed. A systematic and detailed investigation suggests that a third party was involved in supplying fabricated details of potential peer reviewers for a large number of manuscripts submitted to different journals. In accordance with recommendations from COPE we have retracted all affected published articles, including this one. It was not possible to determine beyond doubt that the authors of this particular article were aware of any third party attempts to manipulate peer review of their manuscript.

Received: 25 January 2015 Accepted: 3 March 2015

Published online: 26 March 2015

\section{Reference}

1. Zhang W, Li X, Shang X, Zhao Q, Hu Y, Xu X, et al. Gene expression analysis

in response to osmotic stimuli in the intervertebral disc with DNA

microarray. Eur J Med Res. 2013;18:62.

\footnotetext{
*Correspondence: lixu.aph@gmail.com

Department of Orthopaedics, Anhui Provincial Hospital, No. 17, Road Lujiang,
} Hefei 230001, China 